\title{
Modular Access to Diverse Bridged Indole Alkaloid Mimics via a Gold-Triggered Cascade Dearomative Spirocarbocyclization/[4 + 2] Cycloaddition Sequence
}

\author{
Yi He, ${ }^{\dagger}$ Zhen Liu, ${ }^{\ddagger}$ Danjun $\mathrm{Wu}^{\S}{ }^{\S}$ Zhenghua $\mathrm{Li}^{*},{ }^{\dagger}$ Koen Robeyns, ${ }^{\perp}$ Luc Van Meervelt, ${ }^{\Perp} \odot$ \\ and Erik V. Van der Eycken $*, \dagger, I_{0}$
}

\begin{abstract}
${ }^{\dagger}$ Laboratory for Organic \& Microwave-Assisted Chemistry (LOMAC), Department of Chemistry, KU Leuven, Celestijnenlaan 200F, B-3001 Leuven, Belgium

${ }^{\ddagger}$ State Key Laboratory of Chemical Engineering, East China University of Science and Technology, 130 Meilong Road, 200237 Shanghai, China

${ }^{\S}$ College of Pharmaceutical Science, Zhejiang University of Technology, 18 Chaowang Road, 310014 Hangzhou, China

${ }^{\perp}$ Institute of Condensed Matter and Nanosciences (IMCN), Université Catholique de Louvain, 1 Place Louis Pasteur, B-1348

Louvain-la-Neuve, Belgium

"Biomolecular Architecture, Department of Chemistry, KU Leuven, Celestijnenlaan 200F, B-3001 Leuven, Belgium

IIPeoples' Friendship University of Russia (RUDN University), 6 Miklukho-Maklaya Street, 117198 Moscow, Russia
\end{abstract}

Supporting Information

ABSTRACT: A modular and streamlined synthetic strategy for the generation of bridged indole alkaloid-like heterocycles from easily available building blocks is elaborated. This approach utilizes an Ugi four-component reaction, establishing diversity, followed by an efficient cationic gold-triggered intramolecular cascade non-oxidative dearomative spirocarbocyclization/concerted $[4+2]$ cyclization cascade, furnishing these architecturally complex and distinct bridged heterocyclic scaffolds with good diastereoselectivity.

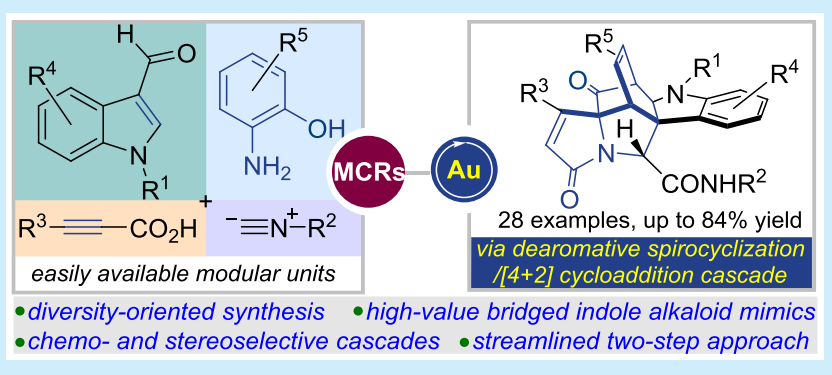

Meanwhile, oxidative ortho-dearomatization of phenols and its derivatives ${ }^{5}$ has extensively been applied as a key step in putative synthetic approaches for caged and fused polycyclic frameworks like diterpenoid alkaloids through the inter- or intramolecular $[4+2]$ cycloaddition of in situ generated reactive masked ortho-benzoquinones ${ }^{6}$ with various dienophiles. ${ }^{7}$ However, to date, integration of an intramolecular oxidative dearomatization followed by a $[4+2]$ reaction with an indole core acting as a dienophile ${ }^{8}$ for the synthesis of bridged indole alkaloid mimics has been surprisingly scarce, probably because of the chemoselectivity issues due to the simultaneous presence of indole and phenol moieties under oxidative conditions.' Notably, there are several reports on the application of gold catalysis in non-oxidative dearomatization reactions of phenol and its derivatives, which efficiently furnish highly functionalized spirocarbocycles containing 2,5-cyclohexadienones or 2,4cyclohexadienones (Scheme 1A). ${ }^{10}$ To the best of our knowledge, the rational combination of gold-catalyzed intramolecular dearomatization and further transformations of spirocarbocycles for the construction of complex 3D scaffolds is rarely explored. ${ }^{11}$ However, this strategy would be promising

Received: April 14, 2019 
Scheme 1. Gold-Catalyzed Dearomatization of Phenols and Further Transformations

A. Gold-catalyzed non-oxidative dearomatization of phenol and its derivatives

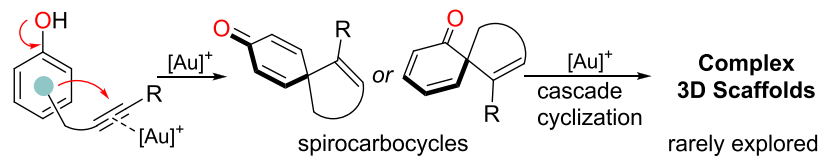

B. This work: Modular access to diverse bridged indole alkaloid mimics

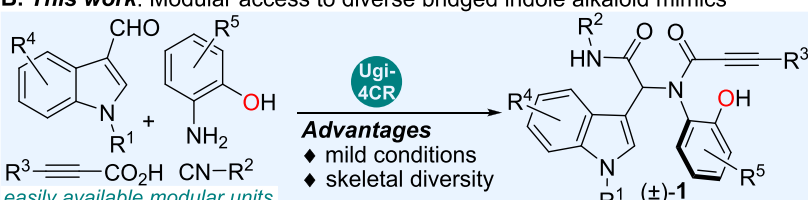

easily available modular units

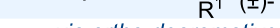
via ortho-dearomative Au

Key challenges:

(i) the chemoselectivity in the presence of $\mathrm{OH}$ group and $\mathrm{C} 3$ of indole

(ii) the regioselectivity in spiro-carbocyclization step (iii) the diastereoselectivity in [4+2] cyclization step
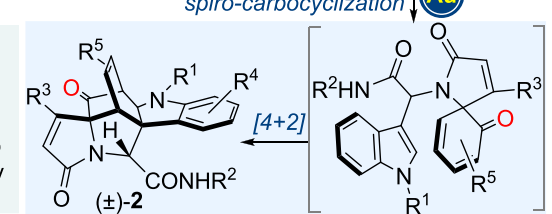

especially considering the high efficiency and broad functional group tolerance of gold catalysts. ${ }^{12}$ Herein, we describe a modular approach for the rapid construction of bridged indole alkaloid-like heterocycles with good building-block diversity in two operational steps including the facile assembly of skeletally diverse precursors through well-developed Ugi four-component reaction (Ugi-4CR) ${ }^{13}$ and efficient gold-catalyzed cascade dearomative spirocarbocyclization/ $[4+2]$ cyclization sequence (Scheme 1B).

Our investigation commenced by examining the envisaged cascade dearomative spirocarbocyclization/ $[4+2]$ cycloaddition process with model substrate $\mathbf{1 a}$, which is easily prepared via Ugi-4CR of indole-3-carboxaldehyde, 2-aminophenol, tert-butyl isocyanide, and 2-butynoic acid. Upon treatment with $10 \mathrm{~mol} \%$ of in situ generated cationic gold catalyst [IPrAuOTf] in $\mathrm{CDCl}_{3}$ at rt for $12 \mathrm{~h}$, the desired bridged indole alkaloid-like heterocycle $2 \mathrm{a}$ was obtained in $40 \%$ yield (Table 1, entry 1). Further increasing the reaction temperature to $70{ }^{\circ} \mathrm{C}$ gave the desired product $2 \mathrm{a}$ in $69 \%$ yield within $2 \mathrm{~h}$ (Table 1, entry 2). The subsequent screening of other gold complexes (Table 1, entries 3-6) revealed that the employment of [(IMes)AuOTf] afforded 2a in the best isolated yield of 73\% (Table 1, entry 6). No amelioration was observed when AgOAc, $\mathrm{AgBF}_{4}, \mathrm{AgSbF}_{6}$, and $\mathrm{AgNTf}_{2}$ served as chloride scavengers for in situ formation of the cationic gold catalysts with $\mathrm{IMesAuCl}$ (Table 1, entries 7-10). Among the evaluation of solvents, toluene and DCE resulted in slightly decreased yields (Table 1, entries 11 and 12), whereas only a trace of $2 \mathrm{a}$ was detected in acetonitrile and methanol (Table 1, entries 13 and 14). A lower catalyst loading of $5 \mathrm{~mol} \%$ delivered $2 \mathrm{a}$ in $41 \%$ yield (Table 1 , entry 15). The separate employment of IMesAuCl or AgOTf led to almost no formation of the desired product 2a (Table 1, entries 16 and 17).

Having optimized the reaction conditions, we sought to evaluate the generality of this gold-catalyzed cascade transformation. Thus, a variety of Ugi adducts 1 were readily synthesized from indole-3-carboxaldehydes and subjected to the optimal reaction conditions on a larger synthetic scale (Scheme $2)$. First, the examination of the influence of the $N$-indole substituent revealed that this procedure worked well with a methyl (2a), a hydrogen (2b), a benzyl (2c), and a phenyl (2d)
Table 1. Optimization of the Cascade Dearomative Spirocarbocyclization/ $[4+2]$ Cycloaddition Process $^{a}$

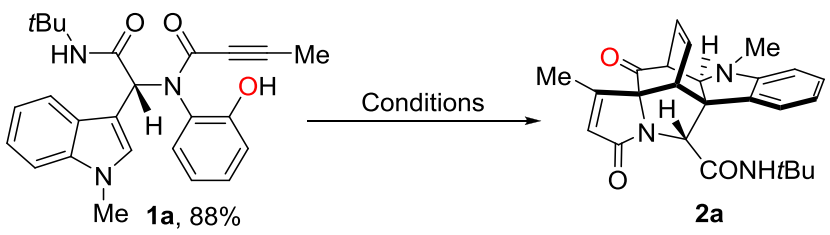

\begin{tabular}{|c|c|c|c|c|c|}
\hline entry & catalyst & solvent & $t(\mathrm{~h})$ & $T\left({ }^{\circ} \mathrm{C}\right)$ & $\begin{array}{l}\text { yield } \\
(\%)^{b}\end{array}$ \\
\hline 1 & IPrAuCl/AgOTf & $\mathrm{CDCl}_{3}$ & 12 & $\mathrm{rt}$ & $40^{c}$ \\
\hline 2 & IPrAuCl/AgOTf & $\mathrm{CDCl}_{3}$ & 2 & 70 & $69^{c}$ \\
\hline 3 & XPhosAuCl/AgOTf & $\mathrm{CDCl}_{3}$ & 2 & 70 & 65 \\
\hline 4 & CyJohnPhosAuCl/AgOTf & $\mathrm{CDCl}_{3}$ & 2 & 70 & 50 \\
\hline 5 & $\left(\mathrm{Ph}_{3} \mathrm{P}\right) \mathrm{AuCl} / \mathrm{AgOTf}$ & $\mathrm{CDCl}_{3}$ & 2 & 70 & 68 \\
\hline 6 & (IMes)AuCl/AgOTf & $\mathrm{CDCl}_{3}$ & 2 & 70 & $73^{c}$ \\
\hline 7 & (IMes)AuCl/AgOAc & $\mathrm{CDCl}_{3}$ & 2 & 70 & 20 \\
\hline 8 & (IMes) $\mathrm{AuCl} / \mathrm{AgBF}_{4}$ & $\mathrm{CDCl}_{3}$ & 2 & 70 & 49 \\
\hline 9 & (IMes) $\mathrm{AuCl} / \mathrm{AgSbF}_{6}$ & $\mathrm{CDCl}_{3}$ & 2 & 70 & 42 \\
\hline 10 & (IMes)AuCl/AgNTf 2 & $\mathrm{CDCl}_{3}$ & 2 & 70 & 55 \\
\hline 11 & (IMes)AuCl/AgOTf & toluene & 2 & 70 & $62^{c}$ \\
\hline 12 & (IMes)AuCl/AgOTf & DCE & 2 & 70 & 66 \\
\hline 13 & (IMes)AuCl/AgOTf & $\mathrm{MeCN}$ & 2 & 70 & trace \\
\hline 14 & (IMes)AuCl/AgOTf & $\mathrm{MeOH}$ & 2 & 70 & trace \\
\hline $15^{d}$ & (IMes)AuCl/AgOTf & $\mathrm{CDCl}_{3}$ & 2 & 70 & 41 \\
\hline 16 & (IMes) $\mathrm{AuCl}$ & $\mathrm{CDCl}_{3}$ & 2 & 70 & trace \\
\hline 17 & AgOTf & $\mathrm{CDCl}_{3}$ & 2 & 70 & trace \\
\hline
\end{tabular}

${ }^{a}$ Unless otherwise stated, all reactions were performed with 1a $(0.05$ mmol) and a catalyst loading of $10 \mathrm{~mol} \%$ in a screw-cap vial with solvent $(1 \mathrm{~mL})$. ${ }^{b}$ Yields based on ${ }^{1} \mathrm{H}$ NMR analysis using $2,4,6-$ trimethoxybenzaldehyde as internal standard, and the diastereomeric ratio of $2 \mathrm{a}$ is over $20: 1$ in all reactions. ${ }^{c}$ Isolated yields. ${ }^{d}$ Catalyst loading of $5 \mathrm{~mol} \%$. IMes = 1,3-bis(2,4,6-trimethylphenyl)imidazole2-ylidene, $\mathrm{DCE}=1$,2-dichloroethane.

group. However, an electron-withdrawing substituent such as a benzenesulfonyl group gave the bridged heterocycle $2 \mathrm{e}$ in a diminished yield of $35 \%$, and even no product $2 \mathrm{f}$ was obtained in the case of an acetyl group, suggesting that not unexpectedly the C3 nucleophilicity of the indole nucleus plays a crucial role in the current process. Next, the high tolerance for the $\mathrm{R}^{2}$ substituent of the secondary amide, derived from various aliphatic $(\mathbf{2} \mathbf{g}-\mathbf{k})$ and aromatic $(\mathbf{2} \mathbf{l}-\mathbf{m})$ isonitriles, was observed. Similarly, the effect of the $\mathrm{R}^{3}$ substituent of the tertiary propiolamide was investigated. A substituent-free propiolamide moiety (2n) is incompatible with this process. The propiolamide moieties bearing alkyl groups such as ethyl (2o), n-propyl $(2 \mathbf{p})$, and $n$-butyl (2q) were all well-converted into the desired product in $55-62 \%$ yield. However, a bulky phenyl-substituted propiolamide moiety offered the target compound $2 \mathbf{r}$ in a lower yield of $35 \%$. Subsequently, the electron-donating $(\mathrm{Me}, \mathrm{OMe})$ or electron-withdrawing $(\mathrm{F}, \mathrm{Br}, \mathrm{I})$ substituents $(\mathbf{2 s - \mathbf { x }})$, installed on the phenyl ring of the indole moiety, were evaluated and also appeared to be well-tolerated. Notably, the Ugi adduct bearing a pyrrolo[2,3-b]pyridine ring system is also applicable in this cascade cyclization, delivering the desired product $2 y$ in $30 \%$ yield. Unfortunately, the steric effect of a methyl substituent on the $\mathrm{C} 2$ of the indole moiety led to the failure of the formation of product $\mathbf{2 z}$. The bridged heterocycles $\mathbf{2 a a}-\mathbf{a e}$ with various substituents $(\mathrm{Me}, \mathrm{Ph}, \mathrm{F}, \mathrm{Cl})$ on both sides of the newly formed double bond could be produced in moderate to good yields of $50-75 \%$. Additionally, the structures of compounds $\mathbf{2 b}, \mathbf{2 a a}$, 
Scheme 2. Substrate Scope of the Cascade Dearomative Spirocarbocyclization/ $[4+2]$ Cycloaddition Process $^{a}$

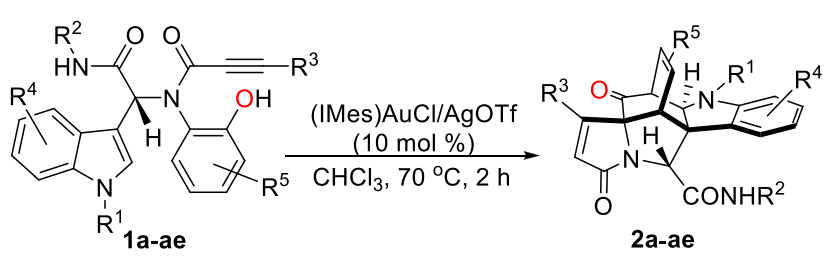

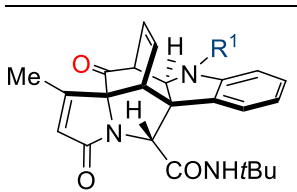

2a, $\mathrm{R}^{1}=\mathrm{Me}, 73 \%$ (d.r. $>20: 1$ )

2b, $R^{1}=H, 65 \%$ (d.r. $>20: 1$

2c, $\mathrm{R}^{1}=\mathrm{Bn}, 58 \%$ (d.r. $>20: 1$ )

2d, $R^{1}=P h, 84 \%$ (d.r. $=10: 1$ )

2e, $R^{1}=$ Bs, $35 \%$ (d.r. $>20: 1$

2f, $R^{1}=A c, 0 \%{ }^{b}$

2n, $\mathrm{R}^{3}=\mathrm{H}, 0 \%$ (d.r. $>20: 1$ )

2o, $\mathrm{R}^{3}=\mathrm{Et}, 62 \% \quad$ (d.r. $=10: 1$ )

2p, $\mathrm{R}^{3}=n \mathrm{Pr}, 55 \%$ (d.r. $>20: 1$ )

$2 \mathrm{q}, \mathrm{R}^{3}=n \mathrm{Bu}, 60 \%$ (d.r. $>20: 1$ )

$2 r, R^{3}=P h, 35 \%$ (d.r. $>20: 1$ )

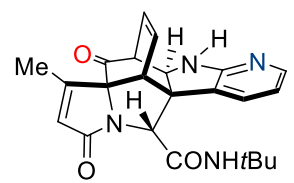

$2 y, 30 \%$ (d.r. $=5: 1$ )

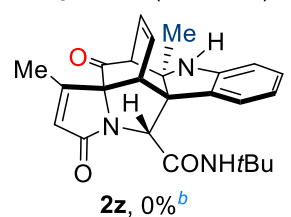

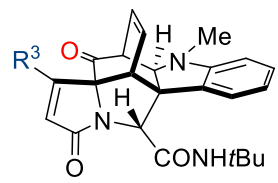

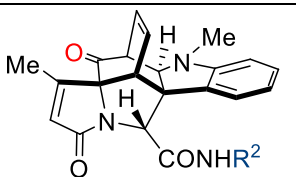

2g, $R^{2}=$ Cy, $63 \%$ (d.r. $>20: 1$ )

2h, $\mathrm{R}^{2}=n \mathrm{Bu}, 67 \%$ (d.r. $>20: 1$ )

2i, $R^{2}=B n, 43 \%$ (d.r. $=10: 1$ )

2j, $R^{2}=T M B, 56 \%$ (d.r. $>20: 1$ )

2k, $\mathrm{R}^{2}=\mathrm{Ad}, 68 \%$ (d.r. $>20: 1$ )

2I, $\mathrm{R}^{2}=p$-MeOPh, 76\% (d.r. = 15:1)

$2 \mathrm{~m}, \mathrm{R}^{2}=2-\mathrm{Np}, 40 \%$ (d.r. $>20: 1$ )

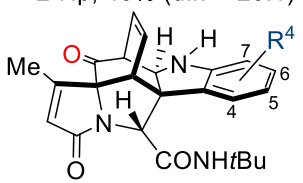

2s, $R^{4}=4-B r, 62 \%$ (d.r. $>20: 1$ )

2t, $\mathrm{R}^{4}=5-\mathrm{OMe}, 56 \%$ (d.r. $>20: 1$ )

$2 u, R^{4}=5-B r, 57 \%$ (d.r. > 20:1)

$2 v, R^{4}=5-F, 65 \%$ (d.r. $>20: 1$ )

$2 w, R^{4}=7-I, 72 \%$ (d.r. $>20: 1$ )

2x, $\mathrm{R}^{4}=7-\mathrm{Me}, 40 \%$ (d.r. $>20: 1$ )

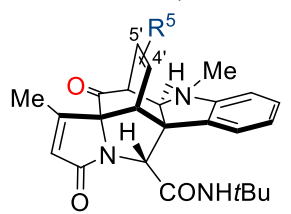

2aa, $R^{5}=4^{\prime}-\mathrm{Me}, 75 \%$ (d.r. $>20: 1$ )

2ab, $R^{5}=5^{\prime}-\mathrm{Me}, 56 \%$ (d.r. $>20: 1$ )

2ac, $R^{5}=4^{\prime}-F, 67 \%$ (d.r. $>20: 1$ )

2ad, $R^{5}=4^{\prime}-P h, 53 \%$ (d.r. $>20: 1$ )

2ae, $\mathrm{R}^{5}=4^{\prime}-\mathrm{Cl}, 50 \%$ (d.r. $=5: 1$ )
${ }^{a}$ All reactions were run with $1 \mathrm{a}-\mathbf{a e}(0.20 \mathrm{mmol})$ and $10 \mathrm{~mol} \%$ of (IMes) $\mathrm{AuCl} / \mathrm{AgOTf}$ in a screw-cap vial with $\mathrm{CHCl}_{3}(2 \mathrm{~mL})$ for $2 \mathrm{~h}$ at $70{ }^{\circ} \mathrm{C}$; all yields are isolated yields. Diastereomeric ratios were determined by ${ }^{1} \mathrm{H}$ NMR spectral analysis. ${ }^{b}$ Decomposition of the precursor was observed. $\mathrm{Bs}=$ benzenesulfonyl; $\mathrm{TMB}=1,1,3,3$ tetramethylbutyl; Ad = 1-adamantyl; $\mathrm{Np}=$ naphthyl.

and 2ad were unambiguously confirmed by X-ray crystallographic analysis (Figure 2).

Our efforts next sought to isolate the spirocarbocyclic intermediate for further evaluation of the gold catalysts' role in the $[4+2]$ cyclization. Treating the Ugi adduct laf, derived from benzo[b]thiophene-3-carbaldehyde under standard conditions, afforded the spirocarbocyclic C3-linked benzothiophene $\mathbf{2} \mathbf{a f}^{\prime}$ and the bridged heterocycle $\mathbf{2 a f}$ in yields of 65 and $25 \%$, respectively (Scheme 3 ). Subsequently, the reactivity of the spirocarbocyclic intermediate $\mathbf{2} \mathbf{a f}^{\prime}$ under different conditions was investigated. In the absence of any catalyst or employing (IMes)AuCl/AgOTf (10 mol \%), $\mathrm{AlCl}_{3}(20 \mathrm{~mol} \%)$, or AgOTf (10 mol \%), the desired caged product 2 af was obtained in a similar low yield of $15-20 \%$ at $70{ }^{\circ} \mathrm{C}$ in $2 \mathrm{~h}$. On the contrary, conducting the catalyst-free reaction at $115^{\circ} \mathrm{C}$ for $2 \mathrm{~h}$

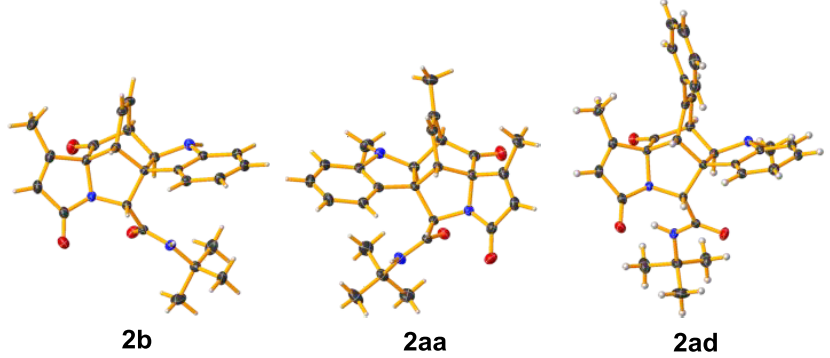

Figure 2. Crystal structure of compounds $2 \mathbf{b}, \mathbf{2} \mathbf{a a}$, and $\mathbf{2 a d}$ with thermal ellipsoids set at the $50 \%$ probability level.

Scheme 3. Capture of Spirocarbocyclic C3-Linked Benzothiophene and Its Further Reaction
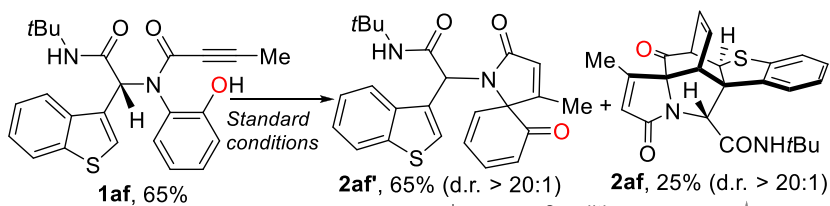

Standard conditions: (af, $65 \%$ (d.r. $>20: 1)$ (af, Conditions

(1a) No catalyst, $70{ }^{\circ} \mathrm{C}, \mathrm{CDCl}_{3}, 2 \mathrm{~h}$.

(1c) $\mathrm{AlCl}_{3}(20 \mathrm{~mol} \%), 70^{\circ} \mathrm{C}, \mathrm{CDCl}_{3}, 2 \mathrm{~h}$.

(1d) AgOTf $(10 \mathrm{~mol} \%), 70^{\circ} \mathrm{C}, \mathrm{CDCl}_{3}, 2 \mathrm{~h}$. $20 \%$ $70^{\circ} \mathrm{C}, \mathrm{CHCl}_{3}, 2 \mathrm{~h}$

(1e) No catalyst, $115^{\circ} \mathrm{C}, \mathrm{DCE}, 2 \mathrm{~h}$.

gave the bridged scaffold in $86 \%$ yield. These observations suggest that the cationic gold species [(IMes)Au]OTf is not involved in this cyclization.

A plausible mechanism for these gold-triggered cascade cyclizations is depicted in Scheme 4 on the basis of these

Scheme 4. Proposed Mechanism

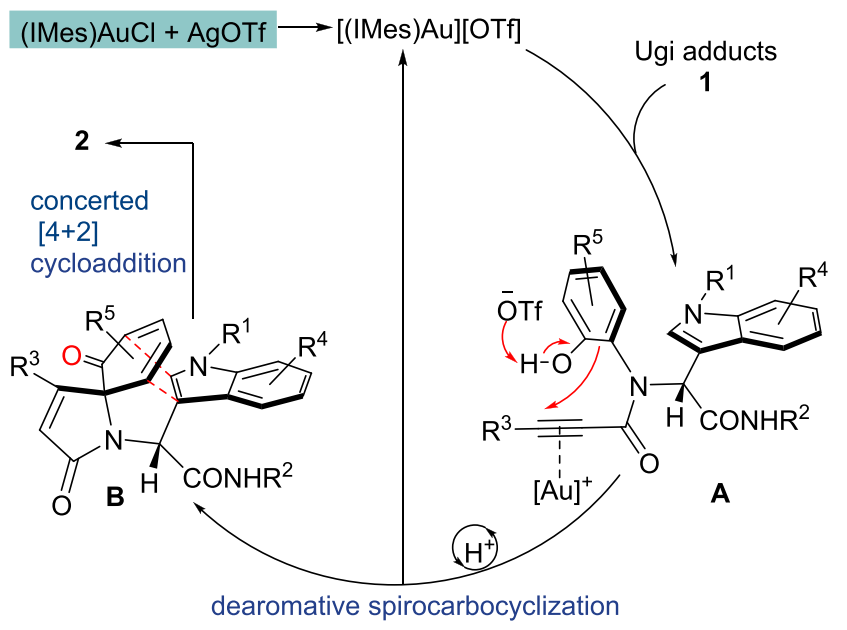

observations and previous investigations. ${ }^{9-11}$ First, a 5-endo-dig nucleophilic attack of the $\mathrm{C} 2$ of the phenol fragment occurs on the cationic gold(I)-activated triple bond, resulting in the formation of the spirocarbocyclic C3-linked indole $\mathbf{B}$. This is followed by an intramolecular $[4+2]$ cyclization of the reactive ortho-benzoquinone, with the indole core most probably without involvement of the gold catalyst, ${ }^{14}$ generating the bridged indole alkaloid-like heterocycle 2. DFT calculations suggest that this intramolecular $[4+2]$ cycloaddition proceeds via a concerted pericyclic process. 
Finally, a large-scale preparation of bridged heterocycle $\mathbf{2 a}$ was performed with $6 \mathrm{~mol} \%$ of gold catalyst, and its further selective hydrogenation was performed as illustrated in Scheme 5. The double bonds in both the cyclohexenone and the $\alpha, \beta$ -

Scheme 5. Hydrogenation of Bridged Heterocycle $2 \mathrm{a}^{a}$

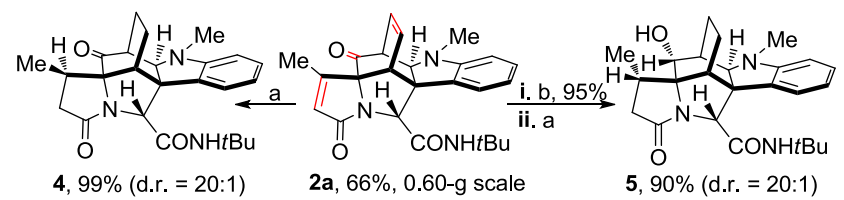

${ }^{a}$ Reaction condition: (a) Pd/C, $\mathrm{H}_{2}(20 \mathrm{~atm}), \mathrm{MeOH}, \mathrm{rt}, 16 \mathrm{~h}$; (b) $\mathrm{NaBH}_{4}, \mathrm{MeOH}, \mathrm{rt}, 0.5 \mathrm{~h}$.

unsaturated $\gamma$-lactam moiety of $\mathbf{2 a}$ were hydrogenated with a $\mathrm{Pd} / \mathrm{C}$ catalyst at $20 \mathrm{~atm}$, producing polyheterocycle 4 in $99 \%$ yield. On the other hand, $\mathrm{NaBH}_{4}$ chemoselectively reduced the carbonyl group of the cyclohexenone, and the obtained product was subsequently treated with $\mathrm{Pd} / \mathrm{C}$ catalyst at $20 \mathrm{~atm}$ of $\mathrm{H}_{2}$ for further hydrogenation of the double bonds, affording product 5 in $90 \%$ yield.

In summary, we have elaborated a modular and streamlined approach to construct architecturally complex bridged indole alkaloid-like heterocyclic scaffolds featuring high substituent diversity from easily available modular units. This two-step strategy employs the Ugi-4CR to introduce five diversity points and an efficient gold-triggered intramolecular dearomative cascade cyclization involving a concerted $[4+2]$ cyclization to assemble the bridged nucleus. The rapid generation of 28 bridged indole alkaloid mimics with multiple new stereogenic centers embracing quaternary ones serves as a proof of concept for our approach.

\section{ASSOCIATED CONTENT}

\section{Supporting Information}

The Supporting Information is available free of charge on the ACS Publications website at DOI: 10.1021/acs.orglett.9b01296.

Experimental procedures, characterization data, and copies of NMR spectra for all compounds (PDF)

\section{Accession Codes}

CCDC 1858538-1858540 contain the supplementary crystallographic data for this paper. These data can be obtained free of charge via www.ccdc.cam.ac.uk/data_request/cif, or by emailing data_request@ccdc.cam.ac.uk, or by contacting The Cambridge Crystallographic Data Centre, 12 Union Road, Cambridge CB2 1EZ, UK; fax: +44 1223336033.

\section{AUTHOR INFORMATION}

\section{Corresponding Authors}

*E-mail: ahlzhchem@gmail.com.

*E-mail: erik.vandereycken@kuleuven.be.

ORCID

Luc Van Meervelt: 0000-0003-2186-5209

Erik V. Van der Eycken: 0000-0001-5172-7208

Notes

The authors declare no competing financial interest.

\section{ACKNOWLEDGMENTS}

This work was financially supported by the FWO [Fund for Scientific Research-Flanders (Belgium)], the Research Fund of the University of Leuven (KU Leuven), and RUDN University Program 5-100. Y.H. appreciates the China Scholarship Council (CSC) for providing a doctoral fellowship. L.V.M. thanks the Hercules Foundation for supporting the purchase of a diffractometer through project AKUL/09/0035. All authors thank Prof. Bert Sels at the Center for Surface Chemistry and Catalysis, KU Leuven, for providing the hydrogenation apparatus.

\section{REFERENCES}

(1) (a) Glennon, R. A. Higher-End Serotonin Receptors: 5-HT 5 , 5$\mathrm{HT}_{6}$, and 5- $\mathrm{HT}_{7}$. J. Med. Chem. 2003, 46, 2795-2812. (b) Zhang, M.Z.; Chen, Q.; Yang, G.-F. A Review on Recent Developments of IndoleContaining Antiviral Agents. Eur. J. Med. Chem. 2015, 89, 421-441. (c) Chadha, N.; Silakari, O. Indoles as Therapeutics of Interest in Medicinal Chemistry: Bird's Eye View. Eur. J. Med. Chem. 2017, 134, 159-184. (d) Hamid, H. A.; Ramli, A. N. M.; Yusoff, M. M. Indole Alkaloids from Plants as Potential Leads for Antidepressant Drugs: A Mini Review. Front. Pharmacol. 2017, 8, 96. (e) Dadashpour, S.; Emami, S. Indole in the Target-Based Design of Anticancer Agents: A Versatile Scaffold with Diverse Mechanisms. Eur. J. Med. Chem. 2018, 150, 9-29. (f) Bharate, S. S.; Mignani, S.; Vishwakarma, R. A. Why Are the Majority of Active Compounds in the CNS Domain Natural Products? A Critical Analysis. J. Med. Chem. 2018, 61, 10345-10374.

(2) For selected reviews on the total synthesis of indole alkaloids, see: (a) Zi, W.; Zuo, Z.; Ma, D. Intramolecular Dearomative Oxidative Coupling of Indoles: A Unified Strategy for the Total Synthesis of Indoline Alkaloids. Acc. Chem. Res. 2015, 48, 702-711. (b) Smith, J. M.; Moreno, J.; Boal, B. W.; Garg, N. K. Cascade Reactions: A Driving Force in Akuammiline Alkaloid Total Synthesis. Angew. Chem., Int. Ed. 2014, 54, 400-412. (c) Song, J.; Chen, D.-F.; Gong, L.-Z. Recent Progress in Organocatalytic Asymmetric Total Syntheses of Complex Indole Alkaloids. Natl. Sci. Rev. 2017, 4, 381-396. (d) Kirillova, M. S.; Miloserdov, F. M.; Echavarren, A. M. Total Syntheses of Pyrroloazocine Indole Alkaloids: Challenges and Reaction Discovery. Org. Chem. Front. 2018, 5, 273-287. (e) Zheng, C.; You, S.-L. Catalytic Asymmetric Dearomatization (CADA) Reaction-Enabled Total Synthesis of IndoleBased Natural Products. Nat. Prod. Rep. 2019, DOI: 10.1039/ C8NP00098K.

(3) For selected examples, see: (a) Jones, S. B.; Simmons, B.; Mastracchio, A.; MacMillan, D. W. C. Collective Synthesis of Natural Products by Means of Organocascade Catalysis. Nature 2011, 475, 183-188. (b) Mizoguchi, H.; Oikawa, H.; Oguri, H. Biogenetically Inspired Synthesis and Skeletal Diversification of Indole Alkaloids. Nat. Chem. 2014, 6, 57-64. (c) Wang, X.; Xia, D.; Qin, W.; Zhou, R.; Zhou, X.; Zhou, Q.; Liu, W.; Dai, X.; Wang, H.; Wang, S.; Tan, L.; Zhang, D.; Song, H.; Liu, X.-Y.; Qin, Y. A Radical Cascade Enabling Collective Syntheses of Natural Products. Chem. 2017, 2, 803-816. (d) Jamison, C. R.; Badillo, J. J.; Lipshultz, J. M.; Comito, R. J.; MacMillan, D. W. C. Catalyst-Controlled Oligomerization for the Collective Synthesis of Polypyrroloindoline Natural Products. Nat. Chem. 2017, 9, 11651169. (e) Tu, H.-F.; Zhang, X.; Zheng, C.; Zhu, M.; You, S.-L. Enantioselective Dearomative Prenylation of Indole Derivatives. Nat. Catal. 2018, 1, 601-608. (f) Huang, L.; Cai, Y.; Zhang, H.-J.; Zheng, C.; Dai, L.-X.; You, S.-L. Highly Diastereo- and Enantioselective Synthesis of Quinuclidine Derivatives by an Iridium-Catalyzed Intramolecular Allylic Dearomatization Reaction. CCS Chem. 2019, 1, 106-116.

(4) For post-multicomponent reaction transformations, see: (a) Sharma, U. K.; Sharma, N.; Vachhani, D. D.; Van der Eycken, E. V. MetalMediated Post-Ugi Transformations for the Construction of Diverse Heterocyclic Scaffolds. Chem. Soc. Rev. 2015, 44, 1836-1860. (b) Li, Z.; Zhao, Y.; Tian, G.; He, Y.; Song, G.; Van Meervelt, L.; Van der Eycken, E. V. Synthesis of Novel Imidazole-Based Triheterocycles via a 
Domino Ugi/Michael Reaction and Silver-Catalyzed Heteroannulation. RSC Adv. 2016, 6, 103601-103605. (c) Li, Z.; Sharma, N.; Sharma, U.; Jacobs, J.; Van Meervelt, L.; Van der Eycken, E. V. LigandControlled Product Selectivity in Palladium-Catalyzed Domino PostUgi Construction of (Spiro)polyheterocycles. Chem. Commun. 2016, 52, 5516-5519. (d) Li, Z.; Song, L.; Van Meervelt, L.; Tian, G.; Van der Eycken, E. V. Cationic Gold (I)-Catalyzed Cascade Bicyclizations for Divergent Synthesis of (Spiro)polyheterocycles. ACS Catal. 2018, 8, 6388-6393.

(5) For selected reviews on dearomatization of phenols, see: (a) Zhuo, C.; Zhang, W.; You, S.-L. Catalytic Asymmetric Dearomatization Reactions. Angew. Chem., Int. Ed. 2012, 51, 12662-12686. (b) Zheng, C.; You, S.-L. Catalytic Asymmetric Dearomatization by TransitionMetal Catalysis: A Method for Transformations of Aromatic Compounds. Chem. 2016, 1, 830-857. (c) Wu, W.; Zhang, L.; You, S.-L. Catalytic Asymmetric Dearomatization (CADA) Reactions of Phenol and Aniline Derivatives. Chem. Soc. Rev. 2016, 45, 1570-1580. (d) Sun, W.; Li, G.; Hong, L.; Wang, R. Asymmetric Dearomatization of Phenols. Org. Biomol. Chem. 2016, 14, 2164-2176. (e) Reddy, C. R.; Prajapti, S. K.; Warudikar, K.; Ranjan, R.; Rao, B. B. Ipso-Cyclization: An Emerging Tool for Multifunctional Spirocyclohexadienones. Org. Biomol. Chem. 2017, 15, 3130-3151.

(6) For reviews on masked ortho-benzoquinones, see: (a) Singh, V. Spiroepoxycyclohexa-2, 4-Dienones in Organic Synthesis. Acc. Chem. Res. 1999, 32, 324-333. (b) Liao, C.-C.; Peddinti, R. K. Masked OBenzoquinones in Organic Synthesis. Acc. Chem. Res. 2002, 35, 856866. (c) Magdziak, D.; Meek, S. J.; Pettus, T. R. R. Cyclohexadienone Ketals and Quinols: Four Building Blocks Potentially Useful for Enantioselective Synthesis. Chem. Rev. 2004, 104, 1383-1430. (d) Harry, N. A.; Saranya, S.; Krishnan, K. K.; Anilkumar, G. Recent Advances in the Chemistry of Masked Ortho-Benzoquinones and Their Applications in Organic Synthesis. Asian J. Org. Chem. 2017, 6, 945966.

(7) For selected examples on cascade dearomatization/Diels-Alder cycloaddition processes, see: (a) Dong, S.; Zhu, J.; Porco, J. A., Jr. Enantioselective Synthesis of Bicyclo [2.2.2] Octenones Using a Copper-Mediated Oxidative Dearomatization/[4 + 2] Dimerization Cascade. J. Am. Chem. Soc. 2008, 130, 2738-2739. (b) Phipps, R. J.; Toste, F. D. Chiral Anion Phase-Transfer Catalysis Applied to the Direct Enantioselective Fluorinative Dearomatization of Phenols. J. Am. Chem. Soc. 2013, 135, 1268-1271. (c) Parvatkar, P. T.; Kadam, H. K.; Tilve, S. G. Intramolecular Diels-Alder Reaction as a Key Step in Tandem or Sequential Processes: A Versatile Tool for the Synthesis of Fused and Bridged Bicyclic or Polycyclic Compounds. Tetrahedron 2014, 70, 2857-2888. (d) Liu, X.-Y.; Qin, Y. Enabling Syntheses of Diterpenoid Alkaloids and Related Diterpenes by an Oxidative Dearomatization/Diels-Alder Cycloaddition Strategy. Nat. Prod. Rep. 2017, 34, 1044-1050. (e) Good, S. N.; Sharpe, R. J.; Johnson, J. S. Highly Functionalized Tricyclic Oxazinanones via Pairwise Oxidative Dearomatization and N-Hydroxycarbamate Dehydrogenation: Molecular Diversity Inspired by Tetrodotoxin. J. Am. Chem. Soc. 2017, 139, $12422-12425$.

(8) For reviews of indole reacting as a nucleophile, see: (a) Bandini, M.; Eichholzer, A. Catalytic Functionalization of Indoles in a New Dimension. Angew. Chem., Int. Ed. 2009, 48, 9608-9644. (b) Dalpozzo, R. Strategies for the Asymmetric Functionalization of Indoles: An Update. Chem. Soc. Rev. 2015, 44, 742-778. (c) Roche, S. P.; Youte Tendoung, J.-J.; Tréguier, B. Advances in Dearomatization Strategies of Indoles. Tetrahedron 2015, 71, 3549-3591. For examples of indole serving as a dienophile, see: (d) Hsieh, M.-F.; Rao, P. D.; Liao, C.-C. Diels-Alder and Michael Addition Reactions of Indoles with Masked O-Benzoquinones: Synthesis of Highly Functionalized Hydrocarbazoles and 3-Arylindoles. Chem. Commun. 1999, 15, 1441-1442. (e) Martin, D. B. C.; Vanderwal, C. D. Efficient Access to the Core of the Strychnos, Aspidosperma and Iboga Alkaloids. A Short Synthesis of Norfluorocurarine. J. Am. Chem. Soc. 2009, 131, 3472-3473.

(9) (a) Lachkar, D.; Denizot, N.; Bernadat, G.; Ahamada, K.; Beniddir, M. A.; Dumontet, V.; Gallard, J.-F.; Guillot, R.; Leblanc, K.; N'nang, E. O.; Turpin, V.; Kouklovsky, C.; Poupon, E.; Evanno, L.; Vincent, G.
Unified Biomimetic Assembly of Voacalgine A and Bipleiophylline via Divergent Oxidative Couplings. Nat. Chem. 2017, 9, 793-798. (b) Nagaraju, K.; Ma, D. Oxidative Coupling Strategies for the Synthesis of Indole Alkaloids. Chem. Soc. Rev. 2018, 47, 8018-8029.

(10) For examples of gold-catalyzed dearomatization of phenols, see: (a) Aparece, M. D.; Vadola, P. A. Gold-Catalyzed Dearomative Spirocyclization of Aryl Alkynoate Esters. Org. Lett. 2014, 16, 60086011. (b) Nemoto, T.; Matsuo, N.; Hamada, Y. Gold-Catalyzed Carbocyclization of Phenols with a Terminal Alkyne via an Intramolecular Ipso-Friedel-Crafts Alkenylation. Adv. Synth. Catal. 2014, 356, 2417-2421. (c) Wu, W.; Xu, R.; Zhang, L.; You, S.-L. Construction of Spirocarbocycles via Gold-Catalyzed Intramolecular Dearomatization of Naphthols. Chem. Sci. 2016, 7, 3427-3431. (d) Wu, W.-T.; Zhang, L.; You, S.-L. Recent Progress on GoldCatalyzed Dearomatization Reactions. Huaxue Xuebao 2017, 75, 419438. (e) Peruzzi, M. T.; Lee, S. J.; Gagné, M. R. Gold(I) Catalyzed Dearomative Claisen Rearrangement of Allyl, Allenyl Methyl, and Propargyl Aryl Ethers. Org. Lett. 2017, 19, 6256-6259. (f) Nechaev, A. A.; Van Hecke, K.; Zaman, M.; Kashtanov, S.; Ungur, L.; Pereshivko, O. P.; Peshkov, V. A.; Van der Eycken, E. V. Gold-Catalyzed Post-Ugi ipsoCyclization with Switchable Diastereoselectivity. J. Org. Chem. 2018, 83, 8170-8182. (g) Wang, H.; Wang, K.; Xiang, Y.; Jiang, H.; Wan, X.; Li, N.; Tang, B. Gold-Catalyzed Intramolecular Dearomatization of Phenols with Allenoates for the Synthesis of Spirocyclohexadienones. Adv. Synth. Catal. 2018, 360, 2352-2357. (h) An, J.; Lombardi, L.; Grilli, S.; Bandini, M. $\mathrm{PPh}_{3}$ AuTFA Catalyzed in the Dearomatization of 2-Naphthols with Allenamides. Org. Lett. 2018, 20, 7380-7383.

(11) (a) Hashmi, A. S. K.; Frost, T. M.; Bats, J. W. Highly Selective Gold-Catalyzed Arene Synthesis. J. Am. Chem. Soc. 2000, 122, 1155311554. (b) Hashmi, A. S. K.; Rudolph, M.; Siehl, H.-U.; Tanaka, M.; Bats, J. W.; Frey, W. Gold Catalysis: Deuterated Substrates as the Key for an Experimental Insight into the Mechanism and Selectivity ofthe Phenol Synthesis. Chem. - Eur. J. 2008, 14, 3703-3708. (c) Oka, J.; Okamoto, R.; Noguchi, K.; Tanaka, K. Asymmetric Dearomatization of 1-Aminonaphthalene Derivatives by Gold-Catalyzed Intramolecular Double C-C Bond Formation. Org. Lett. 2015, 17, 676-679. (d) He, Y.; Li, Z.; Tian, G.; Song, L.; Van Meervelt, L.; Van der Eycken, E. V. Gold-Catalyzed Diastereoselective Domino Dearomatization/ipsoCyclization/aza-Michael Sequence: A Facile Access to Diverse Fused Azaspiro Tetracyclic Scaffolds. Chem. Commun. 2017, 53, 6413-6416. (e) He, Y.; Li, Z.; Robeyns, K.; Van Meervelt, L.; Van der Eycken, E. V. A Gold-Catalyzed Domino Cyclization Enabling Rapid Construction of Diverse Polyheterocyclic Frameworks. Angew. Chem., Int. Ed. 2018, 57, 272-276.

(12) For selected reviews on gold catalysis, see: (a) Hashmi, A. S. K.; Hutchings, G. Gold Catalysis. Angew. Chem., Int. Ed. 2006, 45, 78967936. (b) Hashmi, A. S. K. Gold-Catalyzed Organic Reactions. Chem. Rev. 2007, 107, 3180-3211. (c) Jiménez-Núñez, E.; Echavarren, A. M. Molecular Diversity through Gold Catalysis with Alkynes. Chem. Commun. 2007, 4, 333-346. (d) Arcadi, A. Alternative Synthetic Methods through New Developments in Catalysis by Gold. Chem. Rev. 2008, 108, 3266-3325. (e) Hashmi, A. S. K. Homogeneous Gold Catalysis Beyond Assumptions and Proposals-Characterized Intermediates. Angew. Chem., Int. Ed. 2010, 49, 5232-5241. (f) Corma, A.; Leyva-Pérez, A.; Sabater, M. J. Gold-Catalyzed Carbon-Heteroatom Bond-Forming Reactions. Chem. Rev. 2011, 111, 1657-1712. (g) Garayalde, D.; Nevado, C. Gold-Containing and Gold-Generated 1,n-Dipoles as Useful Platforms toward Cycloadditions and Cyclizations. ACS Catal. 2012, 2, 1462-1479. (h) Braun, I.; Asiri, A. M.; Hashmi, A. S. K. Gold Catalysis 2.0. ACS Catal. 2013, 3, 1902-1907. (i) Wang, Y.-M.; Lackner, A. D.; Toste, F. D. Development of Catalysts and Ligands for Enantioselective Gold Catalysis. Acc. Chem. Res. 2014, 47, 889-901. (j) Dorel, R.; Echavarren, A. M. Gold (I)-Catalyzed Activation of Alkynes for the Construction of Molecular Complexity. Chem. Rev. 2015, 115, 9028-9072. (k) Pflästerer, D.; Hashmi, A. S. K. Gold Catalysis in Total Synthesis-Recent Achievements. Chem. Soc. Rev. 2016, 45, 1331-1367. (1) Wei, Y.; Shi, M. Divergent Synthesis of Carbo- and Heterocycles via Gold-Catalyzed Reactions. ACS Catal. 2016, 6, 2515-2524. 
(13) (a) Ugi, I.; Meyr, R.; Fetzer, U.; Steinbrucker, C. Studies on Isonitriles. Angew. Chem. 1959, 71, 386. (b) Dömling, A.; Ugi, I. Multicomponent Reactions with Isocyanides. Angew. Chem., Int. Ed. 2000, 39, 3168-3210. (c) Dömling, A. Recent Developments in Isocyanide Based Multicomponent Reactions in Applied Chemistry. Chem. Rev. 2006, 106, 17-89. (d) Ruijter, E.; Scheffelaar, R.; Orru, R. V. A. Multicomponent Reaction Design in the Quest for Molecular Complexity and Diversity. Angew. Chem., Int. Ed. 2011, 50, 6234-6246.

(14) For examples of gold-catalyzed $[4+2]$ cyclization, see: (a) Zhang, S.; Cheng, B.; Wang, S.-A.; Zhou, L.; Tung, C.-H.; Wang, J.; Xu, Z. Gold-Catalyzed Cycloisomerization/1, 5-H Migration/ Diels-Alder Reaction Cascade: Synthesis of Complex NitrogenContaining Heterocycles. Org. Lett. 2017, 19, 1072-1075. (b) McGee, P.; Bétournay, G.; Barabé, F.; Barriault, L. A 11-Steps Total Synthesis of Magellanine through a Gold (I)-Catalyzed Dehydro Diels-Alder Reaction. Angew. Chem., Int. Ed. 2017, 56, 6280-6283.

(15) For more details on the DFT calculations, see the Supporting Information. 